\title{
Airborne gravimetry from a small twin engine aircraft over the Long Island Sound
}

\author{
Robin E. Bell*, Bernard J. Coakley*, and Robert W. Stemp $\ddagger$
}

\begin{abstract}
In January 1990, a test of the feasibility of airborne gravimetry from a small geophysical survey aircraft, a Cessna 404, was conducted over the Long Island Sound using a Bell Aerospace BGM-3 sea gravity meter. Gravity has been measured from large aircraft and specially modified de Havilland Twin Otters but never from small, standard survey aircraft. The gravity field of the Long Island Sound is dominated by an asymmetric positive $30 \mathrm{mGal}$ anomaly which is well constrained by both marine and land gravity measurements. Using a Trimble 4000 GPS receiver to record the aircraft's horizontal position and radar altimeter elevations to recover the vertical accelerations, gravity anomalies along a total of $65 \mathrm{~km}$ were successfully measured. The root mean square (rms) difference between the airborne results and marine measurements within $2 \mathrm{~km}$ of the flight path was $2.6 \mathrm{mGal}$ for 15 measured values. The anomalies recovered from airborne gravimetry can also be compared with the gridded regional free air gravity field calculated using all available marine and land gravity measurements. The rms difference between 458 airborne gravity measurements and the regional gravity field is $2.7 \mathrm{mGal}$. This preliminary experiment demonstrates that gravity anomalies, with wavelengths as short as $5 \mathrm{~km}$, can be measured from small aircraft with accuracies of $2.7 \mathrm{mGal}$ or better. The gravity measurements could be improved by higher quality vertical and horizontal positioning and tuning the gravimeter's stabilized platform for aircraft use.
\end{abstract}

\section{INTRODUCTION}

Gravity measurements provide first-order insights into the structure of both continental and oceanic lithosphere. Typically, gravity measurements are more economical than seismic methods and can be collected rapidly. Much of the earth's surface has been mapped using a land gravimeter. Unfortunately this tech- nique is primarily limited to accessible regions with roads. As a result, large regions of Africa, South America, Greenland, Southeast Asia, and most of the Antarctic remain unmapped.

Airborne gravimetry has become an important tool for reconnaissance surveying of such inaccessible regions during the past decade (Bell et al., 1990; Brozena and Peters, 1988; Brozena, 1984). This technique has been successfully implemented both by the Naval Research Laboratory (NRL) (Brozena, 1984) and Carson Geophysical (Gumert et al., 1985). The airborne gravity surveys of the Weddell Sea (Bell et al., 1990) and parts of the southeastern U.S. (Brozena and Peters, 1988) conducted by NRL have all been flown from a Navy P-3 Orion, a large, four engine aircraft. Carson Geophysical reports high resolution gravity has been collected from both S-61 helicopters and from a specially modified de Havilland Twin Otter (Navazio and Gumert, 1982). That airborne gravity has required a large or specially modified aircraft discouraged other attempts to configure airborne gravity systems.

In January 1990, Lamont-Doherty Geological Observatory installed a gravimeter on an INTERA-KENTING Cessna 404 Titan, for a single flight over the Long Island Sound, as a test of the suitability of a small aircraft as a platform for airborne gravity measurements. The purpose of this paper is to report on the successful collection of airborne gravity data using a BGM-3 sea gravimeter mounted on a Cessna 404 during the survey over the Long Island Sound.

\section{PRINCIPLES OF AIRBORNE GRAVITY}

Airborne gravity measurements are difficult to collect because of the low signal to noise ratio. Geological signals reach a maximum of about $300 \mathrm{mGal}$ across subduction zones while sedimentary basins typically have gravity anomalies of less than $60 \mathrm{mGal}$. The corrections necessary to remove the effects of the moving aircraft from airborne gravity measurements can individually exceed $1000 \mathrm{mGal}$. The advent of the Global Positioning System (GPS) provided the continuous precise positioning necessary for accurately recovering these corrections.

Isolating the earth's signal from the accelerations introduced from the measurement process is the major difficulty in gravity

\footnotetext{
Manuscript received by the Editor May 8, 1990; revised manuscript received April 15, 1991. *Lamont-Doherty Geological Observatory, Palisades, NY 10964. †INTERA KENTING, 380 Hunt Club Rd., Ottawa, Ontario KIG 3N3 Canada

(C)1991 Society of Exploration Geophysicists. All rights reserved.
} 
surveys made from moving platforms. To extract a free air anomaly $\left(A_{\mathrm{FAA}}\right)$ from the accelerations recorded by a gravimeter mounted on an aircraft $\left(A_{\mathrm{m}}\right)$, the horizontal velocity, altitude, and position of the system must be accurately monitored. The velocity, altitude, and position of the aircraft are required to determine the Eötvös correction ( $\left.A_{\text {Eötvös }}\right)$, and accurate altitudes are essential to derive the aircraft vertical accelerations ( $A_{\text {aircraft }}$ ). The airborne measurement must also be corrected for aircraft altitude $\left(A_{\mathrm{FAC}}\right)$ and the theoretical gravity on the geoid $\left(A_{\text {Theo }}\right)$. The accelerations measured by the airborne gravimeter and these components are described by:

$$
A_{\mathrm{m}}=A_{\mathrm{FAA}}+A_{\text {aireraft }}+A_{\text {Eötvös }}+A_{\text {Theo }}+A_{\mathrm{FAC}}
$$

where

$A_{\mathrm{m}}=$ measured acceleration,
$A_{\mathrm{FAA}}=$ free air anomaly,
$A_{\text {aircraft }}=$ aircraft vertical accelerations,
$A_{\text {Eötvös }}=$ Eötvös correction,
$A_{\text {Theo }}=$ theoretical gravity,
$A_{\mathrm{FAC}}=$ free air correction.

Accurate recovery of the aircraft vertical accelerations ( $A_{\text {aircraft }}$ ) is critical for the recovery of free air anomalies with an airborne gravity system. In the marine environment, the vertical accelerations of the gravimeter are assumed to be stationary as the ship travels over the equipotential surface. Subsequently these marine accelerations can be removed by filtering over 3-5 minute intervals. In the airborne environment, vertical accelerations cannot be assumed to be periodic and have wavelengths that correspond closely to geological features. Vertical accelerations, with post-filtering amplitudes of $600 \mathrm{mGal}$ and periods of $0.1-600 \mathrm{~s}$ must be calculated from accurate position data and removed from the measured accelerations. These vertical accelerations are calculated from a variety of altimetry sources. Over water, radar altimeters can be used to recover the position of the aircraft and over land, interferometric GPS solutions have sufficient accuracies for airborne gravity measurements (Mader and Lucas, 1989; Brozena et al., 1989).

The motion of a gravimeter across a rotating earth changes the effective rotation rate of the system and consequently the centrifugal component of the gravity field recorded. This effect is treated by removing a velocity dependent term known as the Eotvös correction ( $A_{\text {Eötvös }}$ (Eötvös, 1953). Including the terms necessary for the height of an aircraft above the geoid, Harlan (1968) derived the Eötvös correction:

$$
\begin{gathered}
A_{\text {Eötvös }}=2 V_{e} \Omega \cos \phi+\frac{V_{n}^{2}}{a}\left[1+\frac{h}{a}+\epsilon\left(2-3 \sin ^{2} \phi\right)\right] \\
+\frac{V_{e}^{2}}{a}\left[1+\frac{h}{a}-\epsilon \sin ^{2} \phi\right]
\end{gathered}
$$

where

$$
\begin{aligned}
& A_{\text {Eötrös }}=\text { Eötvös correction (in mGal), } \\
& \phi \quad=\text { latitude in degrees, } \\
& V_{e}=\text { the easterly component of the platform velocity } \\
& (0.001 \mathrm{~cm} / \mathrm{s}) \text {, } \\
& V_{n} \quad=\text { northerly component of the platform velocity } \\
& (0.001 \mathrm{~cm} / \mathrm{s}) \text {, } \\
& h=\text { the height of the aircraft above the geoid }(\mathrm{cm}) \text {, }
\end{aligned}
$$

$e=\quad=$ the earth's flattening for the reference ellipsoid,

$a=$ semi-major radius of the earth $(\mathrm{cm})$,

$\Omega=$ earth's rotation rate $(\mathrm{rad} / \mathrm{s})$.

For a marine gravity measurement, where the height term is zero, the maximum Eötvös correction is approximately $+1-75 \mathrm{mGal}$ (Bell and Watts, 1986). Due to the higher aircraft velocities and the nonzero height term, the airborne Eötvös correction is much larger than the marine correction and can be as great as 2500 mGal. Like the marine Eötvös correction, the airborne Eötvös correction is primarily dependent upon the vehicle's velocity and heading. Real time pseudo-range solutions provided by the GPS navigation system are sufficent to calculate the Eötvös correction for airborne gravity (Brozena, 1984; Hammer, 1983; Gumert et al., 1985).

Airborne gravity measurements are reduced to sea level assuming a free air gradient of $0.3086 \mathrm{mGal} / \mathrm{m}$. If the source of the gravity signal is close to the reference level relative to the minimum wavelengths observed in the gravity field, little is gained by downward continuing the airborne measurements. In this preliminary experiment, we have chosen not to downward continue our results or upward continue the observed field.

\section{TOOLS FOR THE LONG ISLAND EXPERIMENT}

\section{Gravimeter}

The Bell Aerospace BGM-3 gravity meter system was designed for marine use. From crossover analysis of well navigated marine surveys (Wessel and Watts, 1988), gravity anomalies obtained from this system have been shown to be accurate to better than one mGal (Bell and Watts, 1986). The system is extremely flexible for restricted space installations. In 1986, the system was mounted aboard the NRL P-3 for a survey of the western Weddell Sea (Bell et al., 1990). During the course of two weeks in 1988, the system was installed on two separate small boats to survey pull-apart basins along the Dead Sea Transform system (Ben-Avraham et al., 1989).

To monitor vertical accelerations, the BGM-3 maintains a small proofmass in a constant position in an electromagnetic field. Within the sensor, the current through the restoring coil keeps the mass in a constant position by producing an electromagnetic force which balances the gravitational force. The amount of current required to maintain the null position of the proof mass varies linearly with gravity field changes. The varying current in the restoring coil is digitized and summed over one second intervals. The resulting approximately $25 \mathrm{kHz}$ signal is added to a bias periodically updated with ties to known gravity benchmarks. Each pulse has a resolution of $\sim 4.9 \mathrm{mGal}$. During the Long Island airborne experiment the $1 \mathrm{~Hz}$ data were recorded with a time tag and a system status indicator on a Toshiba 1200 laptop computer.

The sensor is axially symmetric and must be maintained parallel to the local vertical, the direction of the maximum acceleration. A two axis gyro-stabilized platform aligns the system to the local vertical. Each axis of the platform incorporates a rate-integrating gyro and a horizontal accelerometer. The erection time constant of the BGM-3 platform is $66 \mathrm{~s}$, less than the time constant of the Lacoste-Romberg meters used by both NRL and Carson. As the time constant is much shorter, the BGM-3 is more sensitive to course changes and other high horizontal accelerations experienced by the aircraft than 
Lacoste-Romberg meters. These horizontal accelerations may introduce off-leveling errors into the recorded gravity field as first described by Browne (1938). These errors can be corrected with careful monitoring of the aircraft horizontal accelerations with a GPS receiver (Bell, 1989).

On INTERA KENTING's Cessna 404, the BGM-3 electronics including the sensor electronics, the platform electronics, and the data buffer were mounted in a standard $19^{\prime \prime}$ rack secured to a seat slide (Figure 1). The stablized platform was attached to a metal plate adapted to fit into the aircraft seat slide.

\section{Altimeter}

A standard French TRT radar altimeter Model ERT-011 (routinely employed by INTERA KENTING for commercial aeromagnetic surveys) was used to record the aircraft altitude and subsequently used to calculate the aircraft vertical accelerations. This altimeter has a usable range up to $1524 \mathrm{~m}$ above the terrain and a resolution of $30.48 \mathrm{~cm}$ within that range. The absolute accuracy of the system is approximately 1 percent of the height above ground. The aircraft altitude was recorded every $0.25 \mathrm{~s}$ with a resolution of $38 \mathrm{~cm}$. Both the altimetry and positioning data were acquired with the data recording system designed by INTERA KENTING.

\section{Positioning system}

The horizontal position of the aircraft was recorded with a single CA-code Trimble 4000 AX GPS receiver mounted aboard the Cessna 404. Only psuedo-range derived positions were used in this experiment. The absolute positional accuracy of the GPS receiver is dependent upon the number of satellites visible, the geometry of the satellites, and the velocity of the aircraft, as well as whether the receiver is a P-code or CA-code receiver. With a single CA-code receiver, such as used in the Long Island experiment, the accuracy of a single position is typically better than $30 \mathrm{~m}$ and velocities are accurate to better than $10 \mathrm{~cm} / \mathrm{s}$ (Wells et al., 1985: Ashjaee, 1985). GPS derived velocities with accuracies better than $2.5 \mathrm{~cm} / \mathrm{s}$ were documented during the Weddell Sea survey (Bell, 1989). As the satellite geometry deteriorates, both the accuracy of individual positions and the velocity solutions degrade.

\section{Aircraft}

The Cessna 404 Titan is a 12-seat, twin piston engine aircraft (Figure 2). The aircraft is capable of approximately 8 hours of flight endurance. This long endurance capability is important to geophysical surveys, particularly airborne gravity surveys, which are best designed with long straight tracklines. The typical cruising speed of the Cessna 404 is $274 \mathrm{~km}$ per hour. The P-3 Orion, surveying at an average speed of $400 \mathrm{~km}$ per hour, recovered wavelengths as short as $15 \mathrm{~km}$ in the Weddell Sea experiment (Bell et al., 1990). If the P-3 results are indicative of the minimum possible resolution available from airborne gravity measurements at a constant sampling frequency, then the decreased speed of the Cessna 404 suggests a minimum wavelength of less than $10 \mathrm{~km}$.

\section{LONG ISLAND SOUND EXPERIMENT}

Long Island Sound is an east-west trending coastal region of the northeastern U.S., east of New York City. The free air gravity field over Long Island Sound is dominated by an asymmetric $30 \mathrm{mGal}$ positive (Figure 3 ). This north-south trending anomaly is part of a gravity anomaly extending from Georgia to Newfoundland that has been subject to numerous interpretations associated with both the closing of the Proto-Atlantic and the subsequent rifting event beginning in the Triassic (i.e., Bell et al., 1988; Ando et al., 1983).

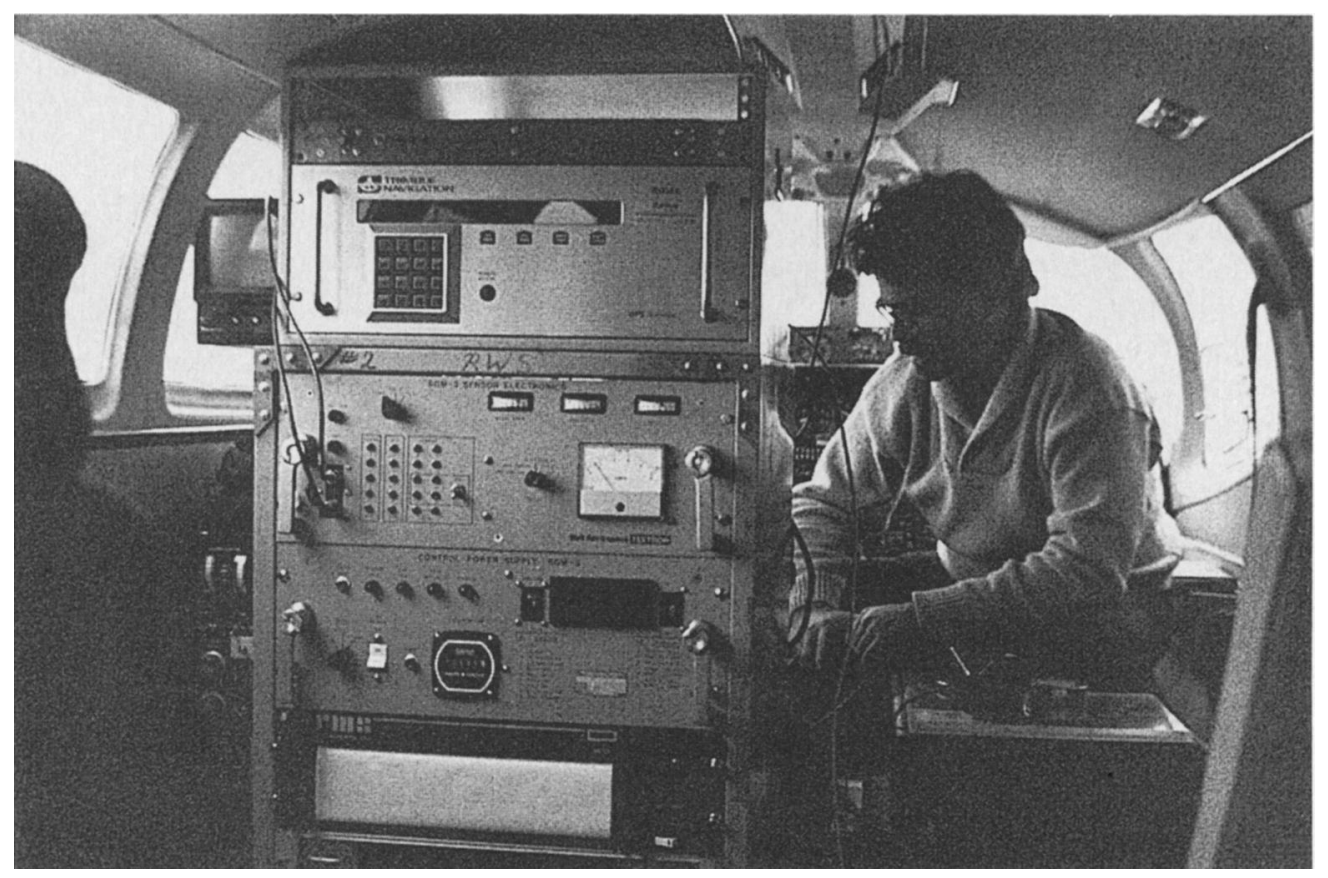

FIG. 1. Lamont-Doherty's BGM-3 mounted on INTERA KENTING's Cessna 404. The sensor electronics and the platform control power supply are mounted on the standard $19^{\prime \prime}$ rack on the left and the stablized platform is located on the lower right. The Trimble $4000 \mathrm{AX}$ is also mounted in the rack. 
In January 1990, a survey of the western Long Island Sound was flown in INTERA KENTING's Cessna 404 using the LamontDoherty Geological Observatory Bell Aerospace BGM-3 sea gravity system as a test of the aircraft suitability (Figure 3 ). The two hour and forty five minute survey was flown at an altitude of $266 \mathrm{~m}$ and an average speed of $283 \mathrm{~km}$ per hour. The weather conditions were ideal with calm winds and little or no turbulence. As the sole source of accurate vertical positioning was the radar altimeter, we were only able to recover gravity data over the water. Over $300 \mathrm{~km}$ of data were collected, but the north-south lines were too short to provide useful airborne gravity measurements. The east-west lines resulted in $65 \mathrm{~km}$ of useful gravity data.

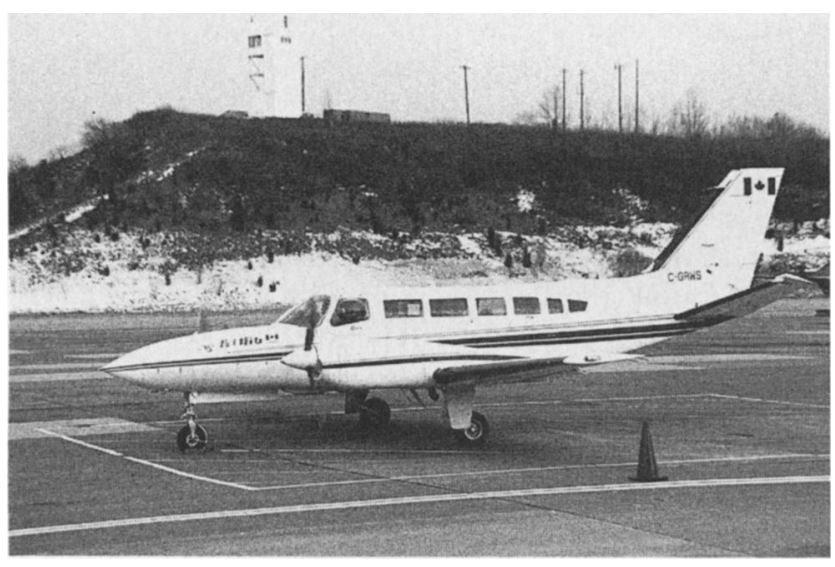

FIG. 2. INTERA KENTING's Cessna 404 configured for airborne gravity surveys.

\section{DATA REDUCTION}

Prior to calculating free air anomalies from the gravity measurements, the altimetry and positioning data were processed to yield $1 \mathrm{~Hz}$ vertical accelerations, altitudes, horizontal velocities and horizontal positions. These data streams were merged with the $1 \mathrm{~Hz}$ BGM-3 output and used to calculate a free air gravity field. The 1967 International Gravity Formula (Moritz, 1968) was used to calculate the theoretical gravity along track for consistency with the marine data set. Harlan's (1968) derivations were the basis of the calculated Eötvös correction. A 30-second Gaussian filter was applied to all inputs at this stage. A windowbased, mouse driven editing program installed on a Sun workstation was used to test the data for timing offsets and remove turns as well as examine the various components for extraneous data points (Bell, 1989). Turns are easily identified as the platform is unable to maintain level and the gravity values rapidly become contaminated by horizontal accelerations. The final processing stage is to apply a median filter to the free air anomalies that removes spikes introduced by a faulty instruction in the data acquisition system.

\section{RESULTS}

The gridded land and marine gravity data provide the ground truth for the airborne survey. The lack of data recovery along the north-south lines precludes any rigorous crossover analysis. The quality of the airborne gravity collected over the Long Island Sound can be quantified two ways. The airborne gravity results can be compared with the observed marine values within two $\mathrm{km}$ of the aircraft ground track by calculating the rms difference between the two. The second method is to compare the results of the airborne experiment to the regional gravity field calculated

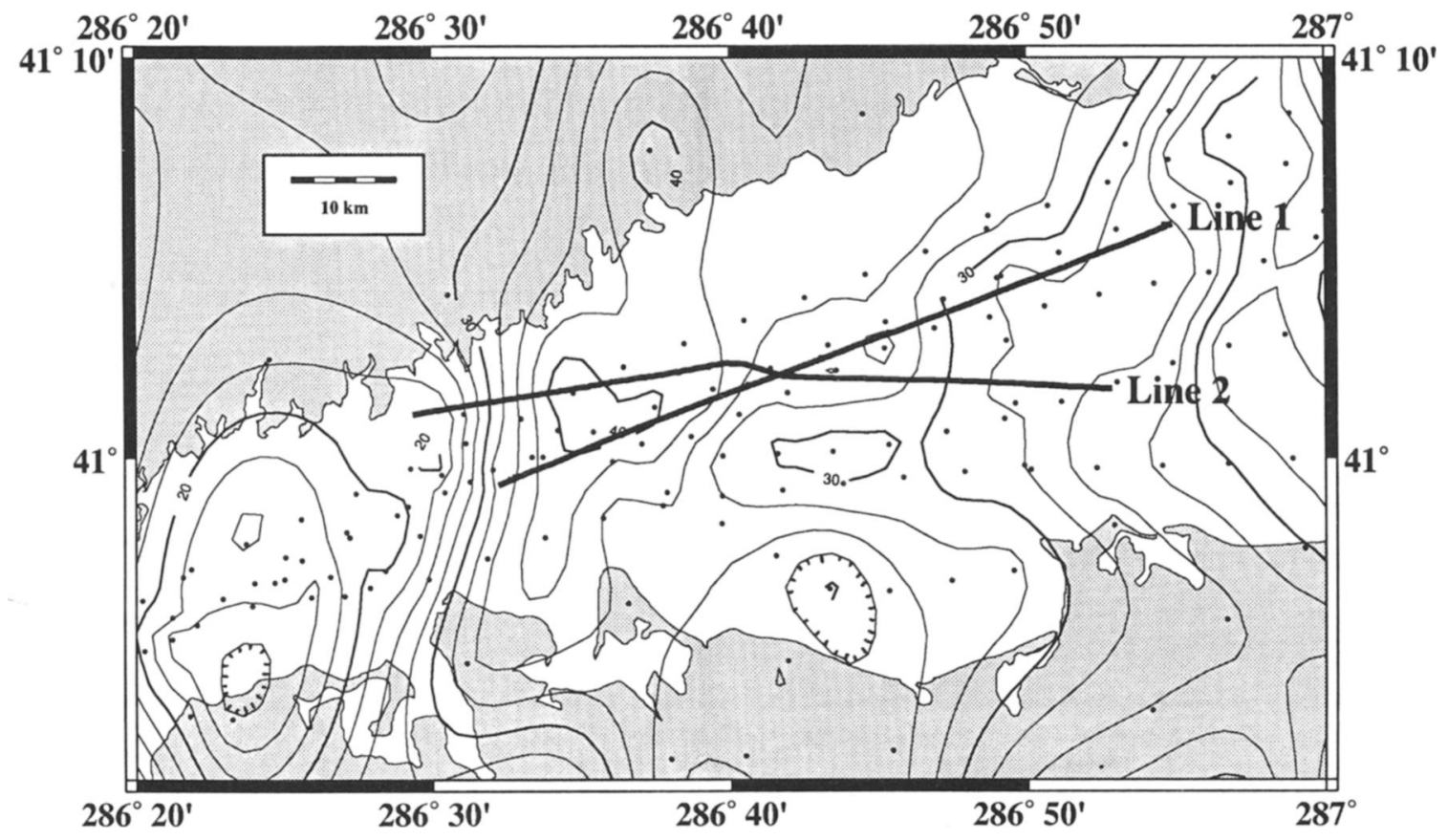

FIG. 3. Free air gravity map of the Long Island Sound contoured at $2.5 \mathrm{mGal}$. The airborne gravity tracks are presented as thick lines. The marine and land gravity data used in the gridding algorithm are shown as small dots. The scale bar in the upper left is $10 \mathrm{~km}$ long with $2 \mathrm{~km}$ ticks. 
from all available gravity data in the region. The gridded regional gravity field is assumed to be the most accurate representation of the field available especially at locations more than $2 \mathrm{~km}$ from individual measurements.

The gravity field of the western Long Island Sound is well constrained by a marine gravity survey (Dehlinger and Hutchinson, 1986) and land gravity coverage on both sides of the Sound. The marine gravity data were collected in 1975 using a Lacoste-Romberg gravity meter. The vessel was navigated with visual and radar fixes. The data were reduced with the 1967 International Gravity Formula (Moritz, 1968) with the Potsdam correction applied. The rms crossover error for 48 crossing tracks is $2.8 \mathrm{mGal}$ with a mean value of $-0.05 \mathrm{mGal}$. The land data were extracted from Lamont-Doherty's data base and have average accuracies of better than $0.1 \mathrm{mGal}$. The land and marine gravity data were merged and gridded using a continuous curvature spline in tension (Smith and Wessel, 1990) with a grid interval of $0.01^{\circ}$ (1.1 kilometer) to produce the free air anomaly map of the western Long Island Sound presented in Figure 3.

Line 1 is compared with both the resampled gridded gravity field and with the observed marine gravity measurements (Figure 4). The error bars on the marine gravity measurements reflect the $2.8 \mathrm{mGal}$ value calculated from the crossover analysis. The solid line is the resampled gridded free air gravity field and the small dots are the observed airborne gravity measurements.
In general, the airborne gravity field compares well with the marine gravity field. The rms difference between the 12 observed marine values and the airborne measurements is $2.7 \mathrm{mGal}$. The difference between the gridded values and the observed airborne gravity measurements for 281 points is $3.0 \mathrm{mGal}$.

The airborne gravity measurements along Line 2 are also compared with the regional gridded field and observed marine gravity data. Line 2 overflew fewer observed marine gravity measurements and included a course change of $15^{\circ}$ between 16 and $20 \mathrm{~km}$ along track. The segment of the line affected by the turn has been highlighted in the figure. The reduced airborne gravity anomalies match the general form of the regional gravity field. The difference between the three observed marine values and the observed airborne gravity anomaly is $1.7 \mathrm{mGal}$, while the difference between airborne results and the 198 gridded values along track is $2.7 \mathrm{mGal}$. If the shaded region, which represents the data collected during the turn, is excluded the rms difference improves to $2.3 \mathrm{mGal}$ for 177 values. This line documents the sensitiviy of airborne gravity measurements to short wavelength gravity anomalies. At $32 \mathrm{~km}$, the gridded regional field includes a distinct change in gradient that is mirrored in the airborne results. The offset in the level of the two similarly shaped anomalies is probably due to the lack of control for the gridded data set close to the airborne gravity track. The significant gradient in the gravity field parallel to the

\section{Line 1}

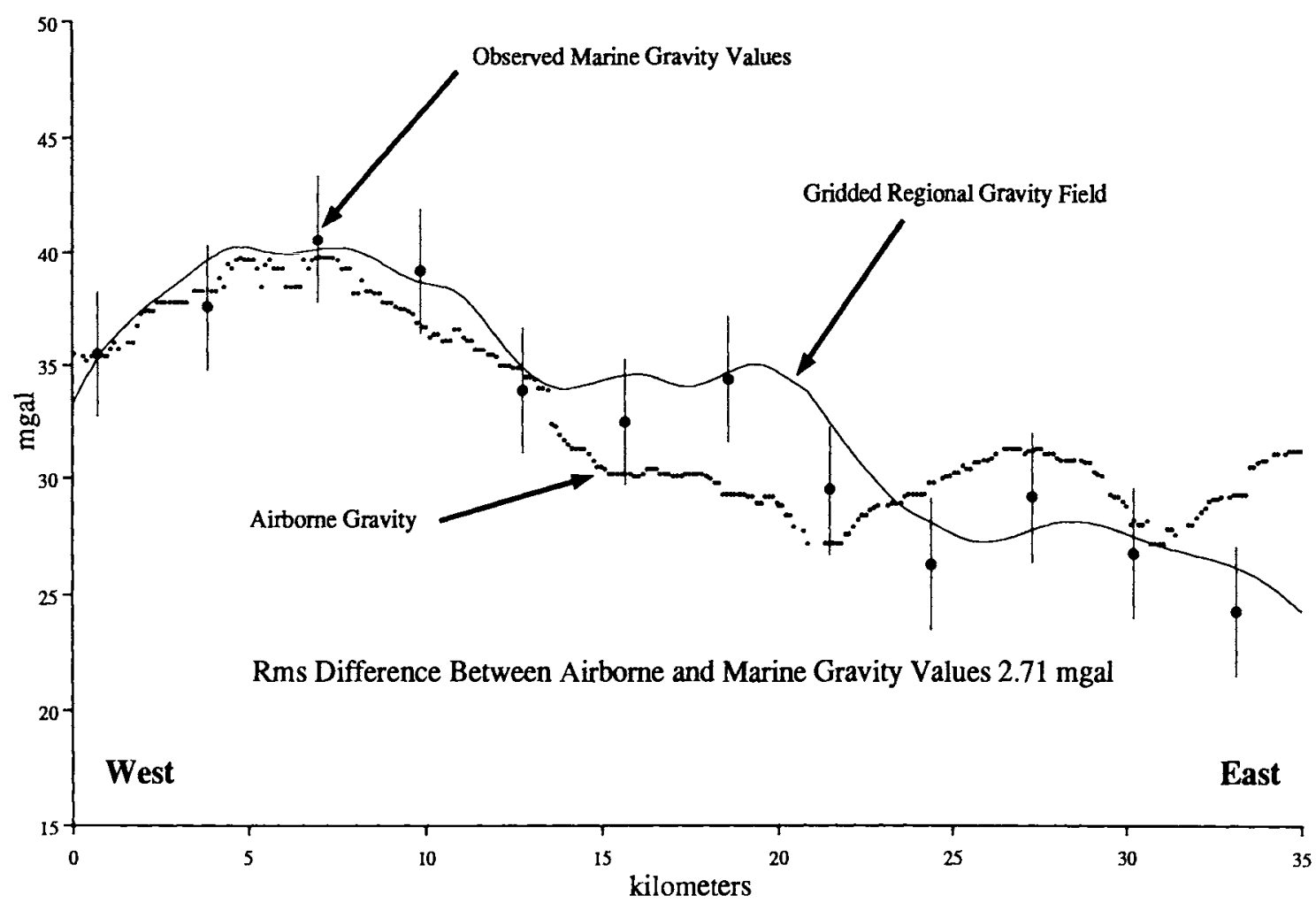

FIG. 4. Comparison of the airborne gravity measurements (small dots) with the observed marine gravity values (large dots) and with the gridded gravity field (light lines) along Line 1 . The error bars on the marine values are based on the analysis of the discrepancy at crossovers. 
tracks may also account for some of the discrepancy between the two data sets.

The results for the entire project can be summarized by calculating the difference between the airborne gravity measurements with both the marine observations and the regional gridded gravity field. The rms difference between the fifteen observed marine values and the airborne gravity field is $2.6 \mathrm{mGal}$. The difference for the 458 gridded free air anomaly values and the along track airborne gravity is $2.7 \mathrm{mGal}$. In summary, the difference between the airborne gravity field and the marine measurements is about $2.7 \mathrm{mGal}$. Crossover error analysis of the marine data set suggests that the marine data has a similar level of uncertainty. Some of this $2.7 \mathrm{mGal}$ discrepancy between the airborne and marine gravity measurements can be attributed to errors in the marine data base.

\section{DISCUSSION}

The comparison of the airborne gravity data with the individual marine gravity data points and the gridded regional gravity field documents the successful measurement of gravity anomalies from a standard geophysical survey aircraft. Both comparisons suggest that the maximum errors in the airborne gravity data are about $2.7 \mathrm{mGal}$.
The $2.7 \mathrm{mGal}$ discrepancy between the marine data and the airborne data probably is related to internal errors within both data sets. The crossover analysis of the marine data (Wessel and Watts, 1988) revealed that the internal consistency of the marine data was only good to $2.8 \mathrm{mGal}$. The errors in the marine data probably result principally from errors in the navigation used to reduce the gravity. Problems in navigation for underway gravity measurements introduce errors both via the calculation of the Eötvös correction and the ellipsoidal gravity and the comparison of values from different locations. The discrepancies bet ween the airborne and marine data $(2.7 \mathrm{mGal})$ are very similar to the $2.8 \mathrm{mGal}$ internal crossovers for the marine data and may primarily reflect the inherent errors in the marine data.

Some of the discrepancy between the airborne and marine data is due to the differing distance to the source of the anomaly. The steepness of the Long Island Sound anomaly implies that the source may be relatively shallow. A simple, single interface model with a density contrast of $0.3 \mathrm{gm} / \mathrm{cm} 3$ can be used to reproduce the observed anomaly. The interface must include a large $2.7 \mathrm{~km}$ escarpment, possibly marking the edge of a Triassic Rift Basin, to reproduce the anomaly. The rms difference between the surface observation and the gravity field observed at $265 \mathrm{~m}$ is $0.6 \mathrm{mGal}$ along the entire profile.

\section{Line 2}

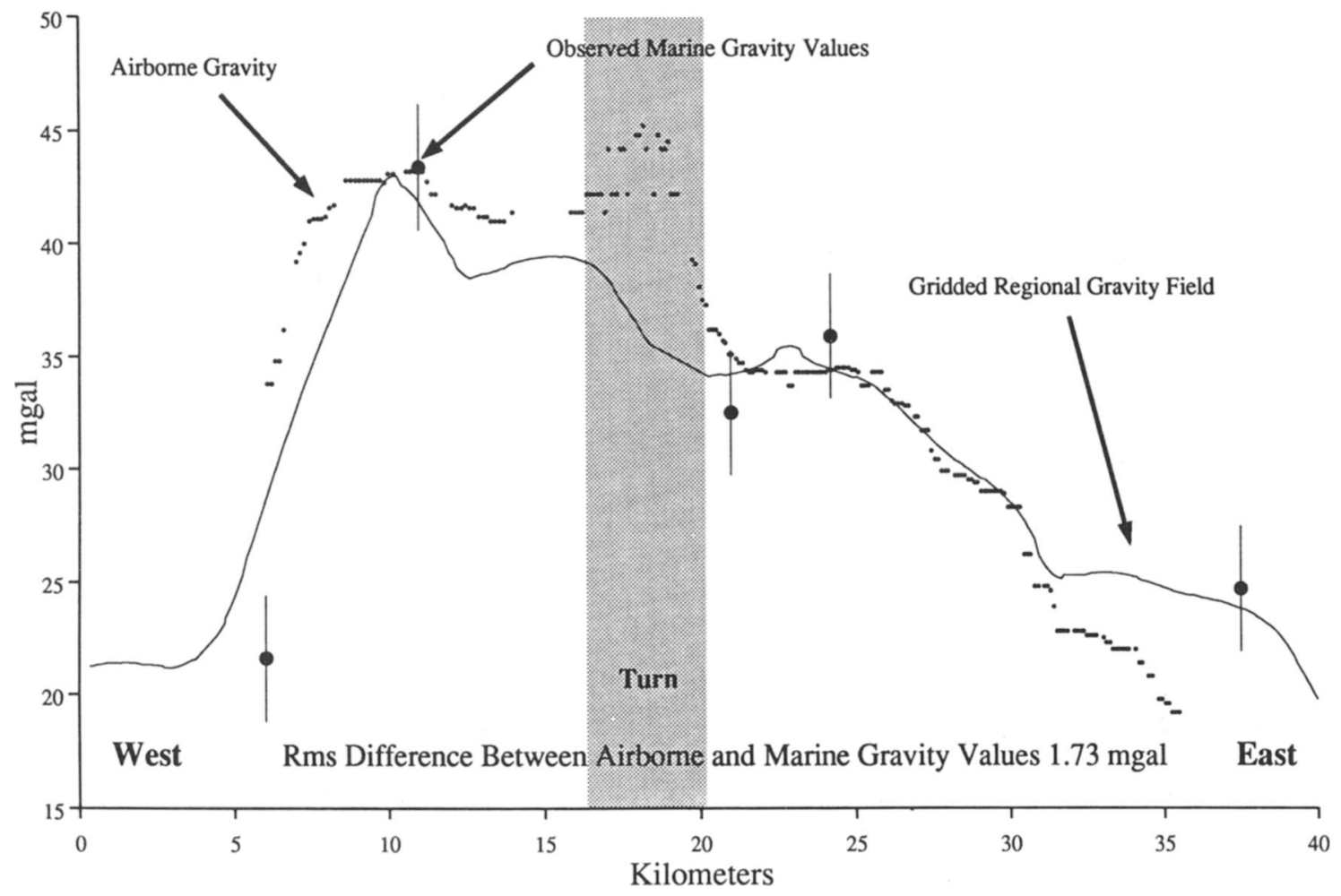

FIG. 5. Comparison of the airborne gravity measurements (small dots) with the observed marine gravity values (large dots) and with the gridded gravity field (light lines) along Line 2 . The error bars on the marine values are based on the analysis of the discrepancy at crossovers. The shaded region between 16 and $20 \mathrm{~km}$ highlights the data effected by a mid-track course change. 
In addition to the discrepancy resulting from the differing levels of observation and the errors inherent in the marine data, some of the discrepancy between the two data sets results from errors in the airborne data. The portion of the $2.7 \mathrm{mGal}$ discrepancy that arises from the airborne data may result from either altimetry errors, horizontal positioning errors, or an inadequately leveled platform.

The vertical positions measured by the radar which are used to calculate the aircraft vertical accelerations probably represent the major source of error in the airborne gravity measurements. The dominant vertical accelerations on the Cessna 404 have periods of 200-500 s with amplitudes of 40-75 mGal corresponding to changes in altitude of 1-4.5 m. Vertical positioning errors of $38 \mathrm{~cm}$ over these periods may account for the $3 \mathrm{mGal}$ discrepancy between the airborne and marine gravity measurements. The 1 percent absolute accuracy of the radar may introduce up to a $2.6 \mathrm{~m}$ error in the absolute vertical locations of the airborne gravity measurements over Long Island Sound. A $2.6 \mathrm{~m}$ error in the vertical position of the aircraft would introduce a $0.6 \mathrm{mGal}$ discrepancy into the reduced airborne gravity field relative to the marine gravity field. The limited resolution and accuracy of the radar during the Long Island Sound experiment could be the major source of error in the airborne results.

A second source of error in the airborne measurements may be the horizontal positioning. Horizontal positioning is used in both calculating the theoretical gravity field and the Eötvös correction. Little error results from miscalculation of the theoretical field as at mid-latitudes a kilometer of positioning error results in $0.8 \mathrm{mGal}$ error and the GPS positioning is good to tens of meters. The Eötvös correction is strongly dependent upon velocity and weakly dependent upon the absolute position. At mid-latitudes a $10 \mathrm{~cm} / \mathrm{s}(0.36 \mathrm{~km} /$ hour $)$ error in determining the aircraft velocity will introduce a $1.27 \mathrm{mGal}$ error into the final gravity field. If the GPS horizontal velocities are only good to $10 \mathrm{~cm} / \mathrm{s}$ (Wells et al., 1985), than a significant portion of the misfit between the airborne gravity and the marine gravity data could be introduced via miscalculations of the airborne Eötvös correction.

The third major source of error arises from the stabilization system. The BGM-3 platform has a short erection period which means it is more sensitive to course changes than gravimeters with long period platforms. The apparently large values during the turn in Line 2 represent an instance where the platform was not level and the accelerometer output was contaminated by the horizontal accelerations of the aircraft. Large outputs from the platform accelerometers are also indicative of an off-level platform.

The quality of airborne gravity measurements from a small aircraft could be enhanced by improving the vertical positioning, improving the horizontal positioning and tuning the BGM-3 platform for airborne use. The advent of differential GPS positioning has significantly improved the positioning accurancy of a dynamic system. With a fixed receiver on the ground in addition to a receiver in the aircraft, it is possible to position the aircraft with an accuracy of $10 \mathrm{~cm}$ with post flight processing (Brozena et al., 1989; Mader and Lucas, 1989). Interferometric GPS (Brozena et al., 1989; Bower et al., 1990) is capable of recovering both the vertical and horizontal positions with sufficient accuracy for airborne gravity measurements. LacosteRomberg gravity meters have long erection periods that permit the platforms to remain level through small course changes.
Increasing the length of the platform period of the BGM-3 will improve the overall performance of the airborne gravity system.

The Long Island experiment was limited to collecting gravity over water, due to the difficulty of recovering an accurate vertical position of the aircraft over land. Tracks over water assume that the water surface is a constant reference surface. The varying topography precludes the use of radar altimetry over land to record the vertical position of the aircraft. The integration of interferometric GPS positioning with larger aircraft has successfully recovered airborne gravity over land. The inclusion of the differential positioning techniques should provide the vertical resolution necessary to measure gravity from small aircraft over land.

\section{CONCLUSIONS}

This test flight in the Cessna 404 over the Long Island Sound was of limited extent, but has demonstrated that gravity anomalies can be recovered from small aircraft with accuracies on the order of $2.7 \mathrm{mGal}$. The gravity system is sufficiently lightweight and compact that aeromagnetic data can be collected simultaneously. The use of a small aircraft greatly increases the number of applications of the airborne gravimetric technique as the expenses of operating a small aircraft are less and small aircraft are able to take off from shorter, more remote runways.

\section{ACKNOWLEDGMENTS}

We would like to acknowledge helpful reviews from J. Halpenny, D. Hutchinson, and one anonymous reviewer. Joe Stennett provided electronics support prior to the survey while Don Bell, pilot, and Dieter Wanassa, observer, assisted us greatly in collecting the data. P. Dehlinger generously provided the unpublished report on the Long Island Sound marine gravity data. P. Wessel's plotting routines were invaluable in producing the final figures for this paper. R. Bell acknowledges support from the Office of Naval Research (N00014-90-J-1059) and the National Science Foundation Division of Polar Programs (DPP-91-00155) for this work. Lamont-Doherty Geological Observatory contribution number 4821 .

\section{REFERENCES}

Ando, C. J., Cook, F. A., Oliver, J. E., and Kaufman, S., 1983, Crustal geometry of the Appalachian orogen from seismic reflection studies, in, Hatcher, Jr., R. D., Williams, H., and Zietz, I., Eds., Contributions to the tectonics and geophysics of mountain chains: Geol. Soc. Am. Memoir, 158, 83-102.

Ashjaee, J., 1985, New results on the accuracy of the C/A code GPS receivers: Proc. First Internat. Symp. on Precise Positioning with the Global Positioning System., U.S. Department of Commerce, 207-225.

Bell, R. E., and Watts, A. B., 1986, Evaluation of the BGM-3 sea gravity meter system onboard $R / V$ Conrad: Geophysics, 51, 1480-1493.

Bell, R. E., Karner, G. D., and Steckler, M. S., 1988, Early Mesozoic basins of eastern North America and their gravity anomalies: The role of detachments during extension: Tectonics, 7, 447-462.

Bell, R. E., 1989, High resolution marine and airborne gravity surveys: Applications to rifted margins: Ph.D. thesis, Columbia University.

Bell, Robin E., Brozena, John M., Haxby, William F., and LaBrecque, John L., 1990, Continental Margins of the Western Weddell Sea: Insights from airborne gravity and Geosat-derived gravity: Contributions to Antarctic Research, 1, 91-102.

Ben-Avraham, Z., Bell, R. E., ten Brink, U., Coakley, B., and Tibor, G., 1989, Structure of two Dead Sea Transform basins from preliminary analysis of marine gravity: EOS, 70, 1312 .

Bower, D. R., Kouba, J., and Beach, R. J., 1990, The spectrum of GPS measurement errors and the accuracy of airborne gravity measurements: Geophysics, 55, 1101-1104. 
Browne, B. C., 1938, The measurement of gravity at sea: Monthly Notes of the Roy. Soc., Geophys. Sup., 4, 271-279.

Brozena, J. M., 1984, A preliminary analysis of the NRL airborne gravimetry system: Geophysics, 47, 1060-1609.

Brozena, J. M. and Peters, M. F., 1988, An airborne gravity study of eastern North Carolina: Geophysics, 52, 245-252.

Brozena, J. M., Mader, G. L., and Peters, M. F., 1989, Interferometric global positioning system: Three dimensional positioning source for airborne gravimetry: J. Geophys. Res., 94, 12153-12162.

Dehlinger, P., and Hutchinson, D. R., 1986, Long Island and Block Island Sound free-air gravity anomaly maps: Unpubl. rep.

Eöt vös, R., 1953, Experimenteller Nachweis der Schwereanderung die ein auf normal geformter Erdoberflache in Ostilicher oder westlicher Richtung bewegter Korper durch diese Bewegung erleidet: Ges. Arbe. Budapest, 293-305. (Published in 1919 in Annalen de Physik.)

Gumert, W. R., Wertz, G. F., and Iverson, R. M., 1985, An application study for using differential GPS in airborne gravity: Proc. First Internat. Symp. on Precise Positioning with the Global Positioning System, U.S. Department of Commerce, 829-832.
Hammer, S., 1983, Airborne gravity is here: Geophysics, 48, 213-223. Harlan, R. B., 1968, Eötvös correction for airborne gravimetry: J. Geophys. Res., 73, 4675-4679.

Madar, G. L., and Lucas, J. R., 1989, Verification of airborne position ing using Global Positioning System carrier phase measurements: J. Geophy. Res., 94, 10175-10181.

Moritz, H., 1968, The geodetic reference system 1967: Allgemeine Vermessungs Nachrichten, 75, 2-7.

Navazio, F., and Gumert, W., Airborne gravity - 1980's: Geophysics, 47, 447, 1982.

Smith, W. H. F., and Wessel, P., Gridding with continuous curvature splines in tension: Geophysics, 55, 1990.

Wells, D. E., Kleusberg, A., Quek, S. H., McCullouch, J., and Hagglund, J., 1985, Precise ship's velocity from GPS: Some test results: Proc. First Internat. Symp. on Precise Positioning with the Global Position System, U.S. Department of Commerce, 799-808.

Wessel, Pal, and Watts, A. B., 1988, On the accuracy of marine gravity measurements: J. Geophys. Res., 93, 393-413. 